\title{
Linguistic and Cultural Interpretation of the Concept "Love" in the Lexicographical Sources of Languages of Different Structures
}

\author{
Gulnaz F. Valiullina, Diana F. Kayumova, Elena V. Valeeva
}

\begin{abstract}
The article is devoted to the comparative study of the linguocultural concept "love" in the English and Tatar languages. In this work, the linguoculturological concept "love" is compared in the Tatar and English languages on the example of lexicographical sources. The relevance of the research topic is determined by the fact that love is one of the most complicated and richly represented in the language of the phenomena of the emotional sphere, which began to attract the attention of linguists and linguoculturological in recent years.

The comparison of different structural languages will reveal both similar sides, since this concept is universal for all languages; and distinctive features, which is explained by the different structure of the languages in question. This article examines the concept of "love" (MBT, love) in ways to transfer lexicographic interpretations of linguistic and cultural concepts in the dictionaries of the Tatar and English, namely in terms of their semantics, as well as conceptual and syntagmatic relations.

The material of the article and the results of the study are of interest to scientists studying concepts in English and Tatar languages. The results can be used in the study of such disciplines as linguoculturology, linguistics, lexicography, etc.
\end{abstract}

Keywords: concept, lexicography, love, Tatar, English.

\section{INTRODUCTION}

Love is one of the significant and richly represented in the language phenomena of the emotional sphere, which began to attract more and more attention of linguists in all countries. In this paper, the linguocultural concept of "love" is compared in the Tatar and English languages on the example of lexicographical sources. [Yusupova, 2015] The comparison of different structural languages will reveal both similar sides, since this concept is universal for all languages; and distinctive features, which is explained by the different structure of the languages in question. This article examines the concept of "love" in ways to transfer lexicographic interpretations of linguistic and cultural concepts in the dictionaries of the Tatar and English, namely in terms of their semantics, as well as conceptual and syntagmatic relations [Galeeva, 2017].

Linguoculturology that emerged at the crossroads of cultural studies, linguistic and cultural studies, ethnolinguistics and sociolinguistics, interacts with them and has its own integrative aspect of studying the problem of language and culture. It sets the aim of systematic presentation of language and culture units in their correlation, works at a deep level of

Revised Manuscript Received on November 08, 2019.

* Correspondence Author

Gulnaz F. Valiullina, Kazan Federal University

Diana F. Kayumova, Kazan Federal University

Elena V. Valeeva, Lobachevsky State University of Nizhni Novgorod semantics, taking into account systematic and integrative approaches to these phenomena. Correlating values of culturally determined units with concepts of national culture, linguoculturological analysis provides them with deep and volume explication.

\section{METHODS}

In the understanding of a simple native speaker dictionary corresponds to the interpretation given in the dictionary $\mathrm{Si}$ Ozhegova "Dictionary of the Russian language": "Dictionary - a collection of words (usually in alphabetical order) with concepts, interpretations or translations into another language." On this side, according to V. G. Gak, the lexicographer acts "as an intermediary between society - a collective carrier of speech - and an individual who, turning to the dictionary for help, as if asking a question to the lexicographer" [Gak, 1977].

The dictionary is also a way to describe language vocabulary in all its features and relationships. Dictionary, as suggested by Sapir, to a large extent should reflect the level of development of culture. Dictionary as the content side of the language always acts as a set of symbols that reflect the cultural background of the society. A large dictionary, he said, is a reliable indicator of the antiquity of certain cultural complexes [Sapir, 1993].

Despite all attempts, a complete description of the lexical system of the language is impossible within a single dictionary. As V. V. Dubichinsky rightly noted that "in any scientific analysis of the vocabulary of the language, some aspects that could represent this phenomenon in a different form, from a different point of view, always remain unaffected" [Dubichinsky, 1998]. Therefore, at the present stage of development of lexicography, we see a lot of all kinds of dictionary publications.

\section{RESULTS AND DISCUSSION}

There are different classifications of dictionaries. We rely on the most famous classification - classification L. V. Shcherba, which is based on a number of oppositions: dictionary of academic type (normative dictionary) and dictionary-reference; encyclopedic dictionary - General dictionary; thesaurus - normal (explanatory or translated); normal (explanatory or translated dictionary) - ideographic dictionary; explanatory dictionary - translated dictionary; non-historical dictionary - historical dictionary.

This classification takes into account a number of parameters:

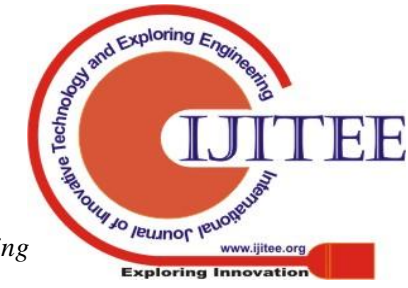


- user dictionary (for example, in the normative dictionary user can find information about the use of words, translated dictionaries are designed for foreign language learners);

- a way of organizing the material in the dictionary (usually in the explanatory dictionary words are arranged alphabetically, and in the ideographic dictionary - based on their meanings); - the number of described languages (monolingual dictionaries are usually monolingual, translation dictionaries - monolingual or multilingual);

- method of material transfer in the dictionary (in the encyclopedic dictionary non-linguistic information is given, drawings and diagrams are used, the normative dictionary contains information relating to the use of the word as a unit of language).

In all the abundance of lexicographical works, two approaches to the description of linguistic units can be distinguished: semasiological (from form to content) and onomasiological (from content units to methods of formal expression of this content) [Kobozeva, 2000; Nurgaliyeva, et al 2018].

The dictionary presents the developed terminology of different types of love that existed in the ancient Greek language. "Eros" is a spontaneous and passionate devotion, an enthusiastic love, directed to the carnal or spiritual, but always looking at its object "from the bottom up" and leaving no room for pity or indulgence. "Filia" is love-friendship, love-the individual's affection for the individual, conditioned by social connections and personal choice. "Storge" is love-affection, especially family, "Agape" - sacrificial and condescending love "to the neighbor" [Philosophical encyclopaedic dictionary, 1983].

Spiritual closeness in love is felt as a constant mental mutual communication, as such an attitude of lovers, when one person directs his thoughts and feelings to another and evaluates his actions, material and spiritual values in a constant ratio with the way a loved one would look at it. Love is a complex dynamic intellectual, emotional and volitional system. True love presupposes the depth of experiences, is distinguished by the fullness of its manifestation and wholeness, inseparability [Philosophical encyclopaedic dictionary, p. 329].

In ethics, love is understood "as such an attitude between people, when one person considers the other as close, related to himself and in one way or another identifies himself with him: feels the need for unification and rapprochement, identifies with him his own interests and aspirations, voluntarily physically and spiritually gives himself to another and seeks to possess him mutually" [Dictionary of ethics, 1983].

In the great psychological encyclopedia are given varieties of love, which are dependent on the object of manifestation of love: 1) brotherly love ("love between equal people") - a fundamental type that forms the basis of all kinds of love; 2) maternal love ("love for a helpless creature"); 3) erotic love; 4) love for yourself; 5) love for God. [Great psychological encyclopedia, 2007].

In the psychological encyclopedic dictionary of M. I. Enikeev, love is considered in a broad sense as "the desire for each other, assuming in its existence respect for each other and even contributing to this." [Enikeev, 2008]. Love is divided into love for the neighbor and love for the distant. The ethical value proclaimed by Christianity, which corresponded to the basic ethical value of antiquity, the love of the neighbor

was at the same time broader in content. Love of neighbor means that one person stands up for another, as well as for himself, without talking about the rights, merits or merits of this person. Love of one's neighbor is not a phenomenon that accompanies compassion; it is a feeling and aspiration that regards another person as a value. In ethics, love for someone distant, sometimes unknown to other people ideal, the implementation of which would raise humanity to a higher level. Love of the far is different from love of the near greatness of moral courage and spiritual generosity [Ayupova, 2017; Araújo, et al 2018].

Thus, in these dictionaries to the concept "love" are given various explanations and classifications presented in the dimension "from sign to concept"; in them love is represented as a complex complex phenomenon, as a deep sense and universal culture, etc. [Tarasova, 2017]. Such a versatile consideration of this phenomenon explains our interest in this concept in the present work.

\section{IV.SUMMARY}

Thus, the vocabulary of the language receives lexicographical interpretation mainly in two dimensions: from sign to concept and from concept to sign. The measurement "from sign to concept" is most fully realized in the explanatory dictionary, the initial task of which is the semantization of the dictionary unit. The second dimension - "from concept to sign" - is reflected in ideographic dictionaries.

Consider the semantic representation of the concept of "love" in philosophical and psychological encyclopedic dictionaries, where the words are presented in the dimension of "from sign to concept."

In the philosophical encyclopedic dictionary love is described as an intimate and deep feeling, as an aspiration to another person, human community or idea. Love includes the impulse and will to constancy, which are formed in the ethical requirement of fidelity. Love arises as the freest and because "unpredictable" expression of the depths of the personality; it cannot be forced or cause or overcome. It should be noted that the importance and complexity of the phenomenon of love are determined by the fact that it intersects the opposites of biological and spiritual, personal and social, intimate and meaningful.

Etymology plays an important role in studying the content of the concept. Therefore, we offer an interpretation of the concepts of "Mahabbat" and "love" in the Tatar and English etymological dictionaries.

$\mathrm{Yu}$. S. Stepanov indicates that a keyword value carries information that is included in a passive, historical layer concept. "The inner form, or etymological feature, or etymology is revealed only to researchers and researchers. But this does not mean that for those who use this concept, this layer of concept content does not exist at all. It exists for them indirectly, as the basis on which the other layers of values arose and are held" [Stepanov, 2001; Godino, et al 2019].

In the short Tatar historical-etymological dictionary of R. G. there are explanations to the words "Yar, soya", which are synonyms of the concept "love". The word "Yar" in its second meaning "beloved; sweet" comes from the Persian word Yar "dus, yaratkan keshe"; in the ancient literary language the word Yaran means 
"accompanying person" [Akhmetyanov, 2001]. Si-œ [su] has the value of "loving caress" in Turkic language from the root si - formed many new words; in the Tatar language from this root is formed such words as sekle (my favorite), Senec (joy) and others [Akhmetyanov, 2001; Kord, et al 2017].

The English etymological dictionary (The Barnhart concept dictionary of etymology) provides the following explanation for the word "love": in the 13th century, the noun love was used as luve; later love (possibly before the 14th century); descended from the old English lufu (before 725). The verb to love 1121, the data used in the luven; later in the form of loven (probably until the 12th century); descended from old English lufian (to 725 years) [The English etymological dictionary, 1995].

\section{CONCLUSIONS}

So, in comparable languages, the concept of "love" has been used for a long time, and has undergone some structural changes in each language. We believe that from the etymological point of view it is a similar feature for the concept of "love" in the Tatar and English languages. [Davletbaeva, 2015]. But, if in English the word "love" is native English, the Tatar language has found many borrowings from other languages, for example, the word "yar" is borrowed from the Persian language.

\section{ACKNOWLEDGEMENTS}

The work is performed according to the Russian Government Program of Competitive Growth of Kazan Federal University.

\section{REFERENCES}

1. A.Sh. Yusupova, G.R. Mugtasimova, G.A. Nabiullina, "Proverbs of the Tatar People as Part of Ethnic Identity", Mediterranean Journal of Social Sciences MCSER Publishing, Rome-Italy, pp. 161-167, 2015.

2. L.I Galeeva, A.G. Sadykova, D.F. Kajumova, G.F .Valiullina, E.L. Iakovleva, "Social and pedagogical conditions of formation the students culture of communication by means of socio-cultural creativity”, Man in India, vol. 97. № 3, pp. 53-65, 2017

3. V. Gak, "Comparative lexicology", pp. 12-15, 1977.

4. E. Sapir, "Selected works on linguistics and cultural science", pp. 275-277, 1993

5. V. Dubichinsky, "Theoretical and practical lexicography", pp. 31-38, 1998.

6. I. Kobozeva, "Lexical semantics", pp. 124-129,2000.

7. "Philosophical encyclopaedic dictionary", pp. 328-329, 1983.

8. "Dictionary of ethics", pp. 168-169, 1983.

9. "Great psychological encyclopedia", pp. 189-190, 2007.

10. M. Enikeev, "Psychological encyclopaedic dictionary", pp. 251-252, 2008.

11. R.A. Ayupova, I. Byiyk, E. Arsenteva, "Motivated Meaning of Phraseological Units with Colorative Components in English and Turkish", The Turkish Online Journal of Design, Art and Communication TOJDACApril 2017 Special Edition, 2017.

12. A.O. Tarasova, A.K. Gizatullina, R.R. Mingazova "Emotional And Expressive Sentences In Tatar And French: Representation As A Semantic Component Of Expressivity", Modern Journal of Language Teaching Methods, pp. 170-176, 2017.

13. Yu. Stepanov, "Constants: Dictionary of Russian culture”, pp. 48-49, 2001.

14. R. Akhmetyanov, "Brief historical and etymological dictionary of the Tatar language”, pp.179-264, 2001.

15. "The Barnhart concise dictionary of etymology", pp. 443-444, 1995.

16. D.N. Davletbaeva, E.A. Smirnova, "Conceptual knowledge in the interpretation of idioms", Journal of Language and Literature, vol. 6, № 1, pp. 240-243, 2015.

17. Kord, H., Noushiravani, Y., Bahadori, M. D., \& Jahantigh, M. Review and Analysis of Telework Perspective in the Administrative Systems. Dutch Journal of Finance and Management, 1(2), 44. (2017)https://doi.org/10.29333/djfm/5820
18. Araújo, C., Henriques, P. R., \& Martini, R. G. Virtual Learning Spaces Creation Based on the Systematic Population of an Ontology. Journal of Information Systems Engineering \& Management, 3(1), 07. (2018).

19. Godino, J. D., Rivas, H., Burgos, M., \& Wilhelmi, M. R. Analysis of Didactical Trajectories in Teaching and Learning Mathematics: Overcoming Extreme Objectivist and Constructivist Positions International Electronic Journal of Mathematics Education, 14(1), 147-161. (2019). https://doi.org/10.12973/iejme/3983Nurgaliyeva, S. Zeynolla, S., Tulenova, U., Zulkarnayeva, Z., \& Yespolova, G. Features of institutional autonomy of the Kazakhstan's universities Opción, 34(85-2), 302-336. (2018). 